\title{
A recusa à desospitalização psiquiátrica: um estudo qualitativo
}

\author{
Refusal of psychiatric de-hospitalization: \\ a qualitative study
}

\author{
1 Faculdade de Medicina \\ de Ribeirão Preto, \\ Universidade de São Paulo, \\ Ribeirão Preto, Brasil. \\ 2 Faculdade de Filosofia, \\ Ciências e Letras \\ de Ribeirão Preto \\ Universidade de São Paulo, \\ Ribeirão Preto, Brasil. \\ Correspondência \\ V. Machado \\ Programa de Saúde na \\ Comunidade, Departamento \\ de Medicina Social, \\ Faculdade de Medicina \\ de Ribeirão Preto, \\ Universidade de São Paulo. \\ Rua Timbiras 453, Santa \\ Bárbara d'Oeste, SP \\ 13456-014, Brasil. \\ vanesmachado@bol.com.br
}

\begin{abstract}
This study is justified based on the large number of individuals currently institutionalized in psychiatric hospitals in Brazil, despite the current proposal for de-hospitalization. The study focused on factors involved in the refusal of dehospitalization, based on reports by patients in a psychiatric hospital with a diagnosis of schizophrenia and preserved verbal capacity. Based on a random selection, six patients answered $a$ semi-structured interview. The interviews were later submitted to thematic content analysis. After reading the transcriptions, the following key thematic contents were extracted: a feeling of freedom even while hospitalized, the material and subjective protection provided by the hospital, and the way institutionalized hospital life is incorporated by patients. The findings can contribute to the drafting of public policies in mental health and to the understanding of this population's subjective dynamics.
\end{abstract}

Mental Health; Schizophrenia; Psychiatric Hospitals
Vanessa Machado ${ }^{1}$

Amábile Rodrigues Xavier Manço ${ }^{1}$

Manoel Antônio dos Santos 2

\section{Introdução}

A conduta terapêutica em relação ao paciente psiquiátrico que prescrevia o asilamento sofreu alterações ao longo do tempo. É a partir da Segunda Guerra Mundial que a desospitalização surge como elemento da assistência psiquiátrica, em resposta a uma convergência de fatores sociais e econômicos que contribuíram para preparar o terreno e desencadear, em vários países, um processo de construção de uma nova política de saúde mental 1 .

Nas décadas de 50 e 60, enquanto países como Estados Unidos, Inglaterra e Itália encontravam-se em um processo de profundas reflexões, resultando no advento do processo de desospitalização, o Brasil vivia sob o regime dos governos militares, que foi marcado por uma política de privatização dos hospitais psiquiátricos, permeada pela malversação e corrupção dos fundos públicos, através de um movimento de internação indiscriminada, que foi caracterizado como "indústria da loucura" 2,3.

Somente em 1978, no contexto do processo de abertura política que culminaria mais tarde com a redemocratização, é que surge o primeiro movimento organizado de questionamento acerca da política de saúde mental, o Movimento dos Trabalhadores em Saúde Mental 4. Influenciada pelo modelo italiano da Psiquiatria Democrática desenvolvido nos anos 70 , surge uma nova concepção de tratamento psiquiátri- 
co, norteando as transformações, que tiveram início no Brasil, oficialmente, a partir de 1987.

As novas políticas de saúde mental impulsionaram, embora de forma localizada, os tradicionais serviços de assistência psiquiátrica a acompanhar os modelos técnicos e teóricos propostos mundialmente. A partir de então, a preocupação em impedir novas cronificações e o trabalho de reabilitação social passam a orientar o atendimento nesses serviços.

Embora exista nacionalmente uma política de desospitalização, assim como uma prática correspondente, observa-se atualmente um número significativo de pessoas que permanecem internadas em hospitais, dentre as quais, há aquelas que se recusam a ser desospitalizadas. Esses pacientes aparentam estar na contramão daquilo que lhes é outorgado como um suposto benefício, em reconhecimento ao seu direito de convívio social. Por essa razão, nos parece essencial ouvi-los, na medida em que os reconhecemos como protagonistas dessa cena contemporânea.

O presente artigo tem como marco teóricoconceitual a concepção que sustenta o paradigma de abordagem psicossocial da loucura, que considera a natureza sócio-histórica dos fenômenos, bem como das práticas assistenciais organizadas em torno dele. De um modo geral, esses princípios orientam o movimento da desinstitucionalização 1,5,6, que representa uma alternativa ao modelo asilar e que, no Brasil, ficou mais conhecida como "reforma psiquiátrica" 4 .

\section{Métodos}

Foi privilegiada uma abordagem de pesquisa qualitativa; os critérios de inclusão na pesquisa foram: ter o diagnóstico psiquiátrico de esquizofrenia, ter capacidade verbal preservada e recusar-se a ser desospitalizado. Assim, foram entrevistados seis pacientes internos do setor de crônicos de um hospital psiquiátrico público do interior de São Paulo, Brasil, sendo uma mulher e cinco homens. As idades dos mesmos variavam de 48 a 80 anos, e o tempo de internação de 15 a 58 anos. Para a seleção dos entrevistados, inicialmente, foi realizada uma análise dos prontuários médicos, levantando a relação de todos os pacientes com diagnóstico de esquizofrenia. A partir dessa relação, seguiu-se um processo de escolha aleatório, a partir de um sorteio de dez pacientes, tendo como testemunhas funcionários do hospital. Em segui- da, foi feito um contato individual com esses pacientes, sendo verificada a recusa à desospitalização e a preservação da capacidade verbal.

Utilizou-se um roteiro de entrevista semiestruturada como instrumento para coleta dos dados. Os dados colhidos neste estudo foram áudio-gravados e, posteriormente, transcritos na íntegra e de forma literal 7. O material colhido foi então submetido à análise de conteúdo temática, sendo o tema, segundo Bardin 8 (p. 105), “a unidade de significação que se liberta naturalmente de um texto analisado segundo critérios relativos à teoria que serve de guia à leitura". Para tanto, procedeu-se uma leitura exaustiva e repetida dos depoimentos, apreendendo as idéias centrais dos temas; em seguida, realizou-se a agregação dos dados mais relevantes nos seus respectivos temas, e, finalmente, foi feita a articulação do corpo teórico com os dados obtidos, propondo interpretações previstas no quadro teórico.

O projeto foi submetido ao Comitê de Ética Médica do hospital onde foi desenvolvida a pesquisa. A coleta dos dados somente teve início diante da autorização do entrevistado por meio do Termo de Consentimento Livre e Esclarecido. Durante a apresentação dos resultados, foi mantido o sigilo quanto à identidade dos pacientes, utilizando-se nomes fictícios para designá-los no presente estudo.

\section{Resultados e discussão}

Para o estabelecimento dos núcleos temáticos, consideramos os motivos que os próprios pacientes relataram como justificativa para a recusa de uma possível desospitalização. Esses motivos emergiram tanto nas falas espontâneas quanto nas falas que respondiam a um questionamento específico sobre o assunto.

Vários relatos apontavam para o hospital como local seguro frente aos perigos da cidade (espaço extra-hospitalar), além de garantir as condições básicas de sobrevivência (abrigo, alimentação, roupa limpa etc.) e de tratamento de saúde (medicação e assistência médica).

“...Aqui é mais sossegado né... num é igual na cidade... lá fora é perigoso... cheio de malandro lá... aqui é mais sossegado" (João).

"Não dá pra morá na cidade... é perigoso demais... tem ladrão... mata gente... aqui agora ficô bom..." (Paulo).

Eventos estressores, tais como roubos e homicídios, decorrentes do processo de urbaniza- 
ção, são apontados, pelos entrevistados, como uma ameaça constante a que se recusam sujeitar-se. Vale considerar que as notícias sobre o mundo extra-hospitalar chegam até os pacientes, principalmente, através dos meios de comunicação de massa (sobretudo televisão e rádio), cujos programas, muitas vezes, privilegiam episódios de violência, tratados em tom sensacionalista.

Considerando o tempo prolongado de institucionalização desses pacientes, pode-se pensar que os recursos de defesa contra os perigos reais são desenvolvidos na medida em que se vive no ambiente social. Enquanto internos, essas habilidades não são necessárias para a sobrevivência.

Na ausência dessas, surge o forte sentimento de insegurança frente ao mundo, o qual, segundo os relatos, aparece como demasiadamente perigoso e hostil, já que, adaptados ao modo de vida asilar, os pacientes não possuem os meios de se autogovernarem fora dos muros do asilo.

"Aqui é melhor que minha casa... porque aqui tem arroz... tem feijão... lá em casa eu passava fome... comi até cocô de fome (...) aqui tem comida... tem roupa" (Madalena).

"Depois que a polícia ponhô eu aqui miorô pra mim... aqui não falta nada pra mim... a vida lá fora tá difícil... porque as coisa tão cara... aqui tenho as coisa" (Espedito).

“Aqui tem o tratamento... remédio... almoço... janta (...) eu sabia que tinha paciente aposentado... mas eu não posso... mas não tem ninguém que cozinha... eu não sei cozinhá... então eu não quero casa não... eu fico no hospital mesmo (ri)" (José).

“A vida lá fora tá difícil por causa de que o ordenado é pouco... aqui é melhor... aqui tem médico todo dia... tem remédio... trata todo dia... aqui tem funcionário à noite" (Mateus).

Conforme indica nossa observação e o próprio relato dos entrevistados, grande parte dos pacientes institucionalizados já não tem problemas de saúde que justifiquem sua internação, tratando-se exclusivamente de uma questão social, seja porque não há uma família que os acolha em suas diferenças, seja porque não há condições econômicas de sobrevivência extra-hospitalar.

Como podemos observar, a instituição psiquiátrica tem a função social de albergue de crônicos, pobres e idosos, sendo que são desenvolvidos mecanismos de tutela cada vez mais sofisticados. De acordo com Fé 9, é comum que a internação responda menos a critérios técnicos do que às privações sociais e familiares, já que, como nos mostra os relatos acima, é comum que, entre pacientes internos, não seja mais identificada doença mental que justifique a internação, mas, sim, uma condição social que inviabiliza o acolhimento do paciente na vida extramanicomial, tal como ausência de programas sociais, trabalhos protegidos ou mesmo vínculo com familiares.

Também foram encontrados relatos que enfatizaram a proteção subjetiva oferecida pelo hospital, como local que garante que não haja contato com o outro de fora.

“Lá fora não podia viver... observação... todo mundo ficava reconhecendo a gente lá... diferente do outro... tudo nóis somo diferente dos outro... pra nóis aqui... os que fala muito não tá muito certo né... os que fala pouco não tá (...) tá com a mente doentia... de preferência fica sério no canto (...) aqui dentro é bom... bom pra nóis... que todo mundo não pode dizer do outro né... todo mundo tem sua doença" (Mateus).

Como podemos notar, o entrevistado diz que se sente observado pelos outros. Tal discurso, que a psiquiatria não hesitaria em designar como paranóide, revela a experiência de estar sendo atravessado por um olhar devassador. O outro pode observá-lo constantemente, invadir seus pensamentos, roubar-lhe as idéias. A fala do entrevistado mostra que, enquanto interno, essa percepção é amenizada, como se os muros de concreto pudessem barrar o olhar do outro, sentido como ameaçador e onisciente, exilando-o e protegendo-o das vivências emocionais que o invadem.

O mesmo entrevistado ainda relata que, fora do hospital, é visto como diferente, enquanto que, entre os internos, essa diferença não é apontada, já que todos estariam na mesma situação. Assim, o hospital tem como função produzir e receber o indiferenciado, alimentando uma ilusão de uniformidade que potencializa o sentimento de pertinência, garantindo a manutenção da relação homogênea entre o indivíduo e o seu grupo. Estar ali, confinado como os outros, é também um modo de não ter que se confrontar com o diferente e, ao mesmo tempo, de não ter que sustentar sua própria diferença em relação ao outro.

Atendo-se ainda a esse relato, nota-se uma incorporação do olhar do outro que o reconhece como desviante, isto é, o próprio paciente identifica-se como tal. A saída vislumbrada, portanto, seria o exílio no local socialmente destinado a acolher esse tipo de desvio, onde há o encontro com outras pessoas em situação semelhante, à procura da forma mais "adaptada" de viver: "os que fala muito não tá muito certo né... os que fala pouco não tá... tá com a mente doentia... de preferência fica sério no 
canto". Como podemos observar no relato desse paciente, a loucura é identificada com o desvio, o afastamento em relação a uma determinada norma de bem viver e conviver; é, por excelência, o reino da desmedida, do excesso ("fala muito") ou seu reverso ("fala pouco").

Desta forma, o hospital aparece como espaço que assegura, no plano real, um certo tipo de proteção, que é, ao mesmo tempo, concreta e subjetiva. Nessa medida, legitima-se a necessidade de uma instância externa (o hospital) para organizar e ordenar a instância interna (o mundo psíquico do paciente).

O fato de alguns pacientes relatarem que já têm liberdade, já que podem ir à cidade e voltar, ou ainda, que, de posse da chave, podem abrir o portão, aparece como fator que justifica a percepção da não necessidade de saída. Para esses pacientes asilados há tantos anos ou mesmo décadas, deixar o hospital não tem um significado de conquista da liberdade, já que eles próprios não se sentem mais segregados do meio social, como indicam alguns depoimentos:

“A gente é livre agora... aqui nóis tá... tá bom aqui pra mim porque eu vô na cidade... vorto... posso passeá" (João).

"Eu tenho liberdade ainda... se eu quiser tenho a chave aqui.. se eu quiser abro o portão lá embaixo... eu tenho uma camisa escrito Louco pela Liberdade... sempre gostei de liberdade... por isso mesmo que ficá preso não adianta" (Mateus).

Possivelmente, nossa concepção de liberdade não coincide com essa que nos parece " $f i$ xada nos limites do asilo", usando o termo de Mannoni 10 (p. 126), ou ainda, como coloca Amarante 11 (p. 53), “uma liberdade intramuros". Com a dificuldade de nos libertar de nossos próprios conceitos, fazemos nossa interpretação, que pode equivocar-se ao não dar conta de apreender qual é a dimensão de liberdade realmente colocada por esses pacientes.

Entendemos que, para esses pacientes, a liberdade está centrada na possibilidade de sair enquanto houver a garantia de voltar ao ambiente institucional, que acaba se constituindo no único suporte concreto de sobrevivência material e psíquica de que eles dispõem. Parece-nos, então, que se trata de sair e regressar à gaiola de ouro que fora aberta. As chaves, as quais os pacientes se referem, são símbolos de liberdade e de recuperação da sanidade no imaginário asilar, porém, de fato, abrem apenas os portões entre um pavilhão e outro. Os portões que dão acesso à rua estão sob guarda constante, sendo que, certamente, não há autorização para permitir saídas solitárias, a não ser em poucos casos previamente determinados.
De acordo com nossa leitura, o vínculo entre os entrevistados e a instituição asilar corresponde à relação estabelecida no espaço familiar, no sentido de que, na família, os filhos (assim como os pacientes) admitem dos pais (entenda-se instituição) algumas restrições à sua liberdade em troca de segurança ${ }^{3}$. Desse modo, a liberdade, que entendemos restrita, é a medida suficiente que faz o equilíbrio entre liberdade e proteção, ou ainda, garante uma liberdade protegida.

Em alguns relatos, apareceram questões tais como: não se dar bem fora do hospital, não gostar da vida extramuros, ou ainda, um desconhecimento sobre o mundo externo:

"Ah eu não se dô bem morá na cidade... eu não gosto... gosto mais daqui mesmo" (João).

"Porque não dá bem lá fora... num dá certo porque... às vez não dá (...) pra eles... é difícil a vida lá fora né... tenho medo de sair daqui e sofrê lá fora... meu marido começô batê em mim... (...)...não tem pra onde ir" (Madalena).

"Faz ano que eu tô cercado aí não sei como é que tá... não sei como é que é lá fora... acho que tanto faz morá lá fora como aqui né" (José).

Tendo passado anos internados no hospital, esses pacientes acabam por adaptar-se à patologia hospitalar, a qual lhes retira os meios de governar-se fora dos muros do asilo, já que o permitido e o proibido são regidos por outras regras que não as vigentes na sociedade 10 .

Adquirem um repertório de comportamentos que são inadequados para o convívio social. Há, ainda, o "vazio emocional”, destacado por Amarante 11 (p. 88) como produto da "mortificação do eu”, "processo de desfiguração, profanação e violação do sujeito institucionaliza$d o$ ". Esse vazio ultrapassa o muro de internação, já que marca profundamente o paciente que fora institucionalizado, inviabilizando as experiências de relações que poderiam vir a estabelecer no decorrer da vida.

Em um dos casos, a doença diagnosticada pelo médico, mais especificamente a esquizofrenia, apareceu como fator impedidor da saída.

"É a doença que eu tenho né... o médico sabe o diagnóstico lá... não sei falá... ele já sabe né... é esquizofrênico né... aqui é melhor pra viver né... sô muito genioso... [lá fora] o povo é mais ativo que a gente né... não tem doença nenhuma mental" (Mateus).

Nesse caso, percebemos a apropriação, por parte do paciente, do discurso médico. Podemos pensar, com Mannoni 10 (p. 71), que "mesmo 'curado' o doente procura conservar uma 'doença' a fim de não se arriscar a que a 'psiquiatria' o abandone", encontrando-se completamente vinculado à instituição, tendo ele pró- 
prio uma maneira de tornar psiquiátrico o seu problema, utilizando-se, para isso, de conceitos e termos médicos que circulam no espaço asilar.

Nesse sentido, é como se o sujeito fosse totalmente apagado em sua subjetividade, para transformar-se na "doença" que o outro (o médico) diz que ele tem ("não sei falá... ele já sabe né...”). O diagnóstico passa, assim, a ser sua referência. A partir de então, acha-se atrelado à fé médica e moral 10. Como podemos observar nos relatos, a referência à doença passa a ser tão forte que chega ao ponto extremo de impossibilitar um convívio social, quando, na verdade, nenhuma doença mental é, por si só, suficiente para justificar tal impossibilidade 3 .

Ainda como elementos reforçadores do estado de profunda alienação a que os pacientes são submetidos, apareceram, nos relatos, a impossibilidade de trabalhar e o fato de já estarem aposentados.

“Não... agora eu não posso trabalhá serviço pesado mais... antes do reumatismo eu tinha vontade de ir embora... mas depois que deu daí eu perdi a vontade... agora eu não vô porque agora ganho por mês" (Paulo).

“...ah a gente tem que morá aqui... porque sim... precisa morá aqui... não vorto mais trabalhá" (Espedito).

"Agora tô bem... tô aposentado (...) tô aposentado" (Mateus).

Possivelmente, esses pacientes entendem que seriam necessários mais recursos financeiros para se sustentarem fora do hospital. Dizem, também, que já estão aposentados, como se ali, então, fosse o local mais apropriado para desfrutarem dessa aposentadoria. Em nosso contexto cultural, aposentar-se geralmente significa retirar-se da vida produtiva, como merecida recompensa por décadas de trabalho árduo e constante. Os pacientes parecem apropriar-se da conotação positiva desse termo para se referirem ao estado de estagnação em que se encontram, já que a aposentadoria é uma condição socialmente aceita e valorizada, atenuando, assim, a desqualificação que ronda o enclausuramento em uma instituição total como o manicômio.

Em contrapartida, alguns relatos explicitaram a percepção da obtenção de algum ganho secundário com a hospitalização:

"Eu gosto daqui" (João).

“Num quero sair daqui... não... quero ficá até morrer aqui... (...) porque eu quero... preciso ficá aqui... muito pobre... aqui subi na vida... hoje vô recebê dinheiro" (Madalena).

"Não... aqui tá bom" (Espedito).

Em alguns depoimentos, transpareceu a idéia de que hoje o hospital está bom, quando comparado com antigamente.
“Era ruim enquanto a gente tava no pátio... depois que mudô pra cá ficou mior” (João).

Há aqueles pacientes que relataram que não querem sair do hospital porque gostam dali e se sentem satisfeitos. Também há quem considere que a internação fez com que "subisse na vida”, já que antes era muito pobre. Nesses casos, segundo os relatos, o hospital se assemelha a um conjunto de serviços de hotelaria, proporcionando boa acomodação, alimentação e benefícios sociais, quando comparado com a anterior condição de origem miserável desses pacientes.

Há relatos de que, nos dias de hoje, é tarde para sair do hospital, pois muito tempo se passou, de modo que se habituaram à vida asilar ou acreditam-se velhos demais para assimilarem mudanças. Outros se referem aos longos anos de internação, que fizeram com que se acostumassem com essa condição, já que, como relata um dos entrevistados, passaram-se mais anos dentro do hospital do que fora. Outro entrevistado aponta o fator idade, sendo que atualmente se sente velho para sair do hospital e adaptar-se às mudanças exigidas pelo mundo externo, o que seria diferente caso fosse mais novo.

"Hoje em dia não quero mais embora daqui... acostumei aqui... levei minha vida aqui... mais tempo do que de moço... vim pra cá com vinte e um anos né... vim pra cá até hoje... tem mais ano dentro desse hospital aqui... portanto acostumei aqui... levei essa vida aqui" (João).

"Hoje preciso porque a perna não ajuda mais andá né... se não, se eu fosse mais novo, eu ia embora né" (Paulo).

Certamente, é comum que, com o avanço da idade, prevaleça uma tendência em reduzir a disposição ou motivação para mudanças bruscas na vida, como seria para esses pacientes a saída do hospital. Além disso, vale considerarmos que o contato com o desconhecido, para qualquer pessoa, incita facilmente temores e insegurança, a ponto de impedir rupturas com antigas posturas e crenças cristalizadas.

Esses pacientes que viveram anos a fio internados explicitam, ao nosso ver, a total identificação com a instituição, que, de fato, tornou-se sua casa. Sua história pessoal, sua própria identidade, está, de certo modo, atrelada ao modo de vida do hospital.

Dessa forma, podemos pensar, como Mannoni 10 (p. 67), que o hospital “acaba por criar uma microssociedade que não consegue comunicar-se com o meio social (os 'doentes' tecnicamente curados resignando-se à hospitalização, permanecendo exilados numa carreira hospitalar de que não podem mais sair)". Então, encer- 
rados em um mundo à parte, impõe-se a dificuldade de romper com tal condição de exílio, um requisito essencial para que pudessem desenvolver condições de se sustentarem no convívio social.

Pelo menos em um caso, ao longo da entrevista, apareceu uma postura ambivalente na resposta do paciente quanto ao seu desejo de sair do hospital.

"Eu tenho vontade de i embora mas eu num quero i embora não... eu tenho vontade de i embora... eu tenho vontade de i embora mas não tem outro lugar pra mim embora... eu vou pra onde? Eu sozinho tenho... (...) eu tenho vontade de i embora mas como não tem jeito de procurá outro lugar eu fico aqui... não quero i embora... mas todos os lugar que eu ficá eu fico bem eu acho bom ficá... eu tenho vontade de sair ...mas eu gosto de ficar aqui... ah se eu precisá ficar aqui eu fico... fico no hospital (...)...eu não falo nada não... pra mim tá tudo numa boa... pra mim tá tudo bem... é isso aî" (José).

Assim, no decorrer de uma das entrevistas, o paciente pôde expor o conflito resultante de desejos aparentemente contraditórios, sendo que, inicialmente, a possibilidade de falar e ser ouvido foi apontada, por ele próprio, como momento importante e raro na instituição. Esse paciente, que a princípio fora convidado a participar da pesquisa por confirmar não ter desejo de sair do hospital, à medida que foi ouvido, evidenciou certo interesse em ser desospitalizado; no entanto, afirma que não poderia deixar a instituição por não ter outro lugar para ir.

De acordo com Calligaris 12, quando o paciente não encontra um mínimo de escuta ou, o que é ainda mais grave, quando encontra uma verdadeira recusa em ser ouvido, acaba por desenvolver um certo tipo de processo degenerativo, o qual leva a um empobrecimento psíquico. Essa situação é facilmente constatada em instituições manicomiais como a que estudamos, dando origem a uma série de dificuldades e limitações às tentativas de reversão do quadro de avançado processo de deterioração mental. Em outro caso, ainda é aberta certa possibilidade...

"Vamo vê com o tempo né... hoje... (faz sinal negativo com a cabeça)" (João).

Esse paciente, soubemos algum tempo depois, teve sua família localizada e encontra-se morando com ela. Isso aconteceu decorrido aproximadamente um ano da entrevista, evidenciando, de forma muito clara, a importância de considerarmos o caráter pontual de nossa abordagem. Ou seja, aquilo que pôde ser captado do paciente fez sentido no momento da interação com o entrevistador, lembrando que é próprio da condição humana ser flexível e aberto a mudanças - que constitui, aliás, um critério de saúde mental.

Em outro caso, o fato de ter passado por inúmeros percalços na vida e ter sobrevivido a essas dificuldades foi valorizado como motivo de vitória.

“...é uma vitória... heroísmo... venci na vida... venci... passei muitos obstáculos ruim né... venci e tô aqui (...) agora" (Mateus).

Enfim, ter sobrevivido aos tempos sombrios no hospital é apontado como uma vitória para esse paciente. Desse modo, a internação é vista como um cruel obstáculo superado na vida desses pacientes, ou melhor, desses sobreviventes. Provavelmente, os eventuais infortúnios de hoje se tornam insignificantes quando comparados com os já vividos em períodos anteriores.

Dessa maneira, a partir dos relatos dos entrevistados, levantamos diversos pontos que contribuem para a elucidação dos sentidos da resignação à hospitalização e da recusa de sair do hospital.

A análise dos relatos nos aproxima do que afirma Basaglia 6 , isto é, que a proposta de desospitalização vem daqueles que outrora enclausuravam, ou seja, do dominador. Os pacientes, por seu lado, apresentam forte resistência em deixar a instituição e dificuldade em manter um convívio social sem a tutela do Estado. Isso ocorre basicamente por duas razões: uma de natureza universal, por terem permanecido por muito tempo institucionalizados, habituandose ao modo de vida asilar; e pelo fato de o manicômio suprir necessidades econômicas e sociais, assegurando a alimentação, o abrigo e os cuidados médicos a pessoas que, muitas vezes, sobrevivem em condições subumanas. É compreensível que isso seja percebido como benefício se levarmos em consideração que vivemos em uma sociedade profundamente desigual, marcada por um abismo que separa ricos e pobres, criando extensas zonas de exclusão social.

Assim, a proposta de desospitalização poderia soar ao paciente como um impasse de difícil desfecho, como podemos observar neste relato: "colocam-me diante de uma escolha: ser soldado e provocar a minha morte, ou permanecer aqui e ter salva a minha vida. Escolho a vida, se bem que esta não seja também a solução" 10 (p. 44).

\section{Conclusão}

De acordo com o que nos foi possível apreender das entrevistas, podemos concluir que a loucura põe em questão não só a experiência singular, mas todo o universo cultural e histórico que a nomeia e a torna reconhecível, de- 
signando-lhe um lugar no conjunto de possibilidades do acontecer humano. Desse modo, entendemos que a abordagem da experiência da loucura e sua institucionalização devem apontar para a sua presença e produção no espaço social e, além disso, deve considerar a dimensão da subjetividade, que são as marcas inconfundíveis de cada sujeito.

A partir da análise das entrevistas, podemos tecer algumas considerações sobre o fenômeno da recusa à desospitalização. Em primeiro lugar, o hospital, na perspectiva dos pacientes, é entendido como lugar que garante uma proteção. Essa proteção é apreendida de diversas formas e se traduz nas condições físicas que oferece aos pacientes, assegurando o acesso à alimentação, abrigo e vestimentas. Também revela a assistência médica proporcionada para os pacientes 24 horas por dia, com direito à medicação, exames e tratamentos clínicos e psiquiátricos. $\mathrm{O}$ hospital ainda funciona como uma forma de proteção subjetiva para os pacientes.

Fica claro, como já foi demonstrado em outros tantos trabalhos 1,4,11,13, que a simples abertura dos serviços de saúde mental não coíbe o empobrecimento psíquico desse pacientes. $\mathrm{O}$ processo de transformação do paradigma asilar rumo a um modelo de atenção psicossocial requer, além da substituição prática do serviço, a "desconstrução do contágio cultural em termos das teorias e valores a ele vinculados" 14 (p. 179).

Com isso, referimo-nos à necessidade da superação das verdades produzidas pelo modelo de racionalidade da ciência moderna 11 , como as noções de incapacidade, periculosidade e inimputabilidade supostamente inerente ao psicótico, que, conseqüentemente, levam à objetivação do homem e às diversas formas de tutela $3,11,14,15$. Segundo Amarante 11, são estes préconceitos científicos que a própria sociedade assimila e reproduz como verdade que fundamenta o imaginário social acerca da loucura.

Atualmente, existem movimentos que buscam, de fato, romper com esse imaginário a partir da "inserção da loucura no espaço social" 11 (p. 90), proporcionando o estreitamento dos laços com o mundo e "agenciando a presença do psicótico nos lugares que lhe são fechados: a família, o trabalho, o lazer, a arte, a lei" 3 (p. 97).

Assim, há iniciativas de construções de novas estruturas sociais, como centros de saúde mental territoriais, cooperativas de trabalho, centros de convivência que oferecem oficinas de arte e música, financiamento e parcerias para criação de cursos de qualificação profissional, criação de lares abrigados e pensões protegidas 3,11 . Ainda pode ser citado o movimento mineiro que envolve uma entidade civil (Fó- rum Mineiro de Saúde Mental), que participa da formulação de iniciativas políticas, jurídicas e culturais que favoreçam a possibilidade da presença da loucura na cidade 3 .

Com esse tipo de movimento, caracterizado mais como uma inovação na cultura do que uma sofisticação científica, podemos pensar na possibilidade de instituir formas realmente alternativas de tratamento. Ou ainda, como coloca Pelbart 16 (p. 135), "libertar o pensamento da racionalidade carcerária é tarefa tão urgente quanto libertar nossas sociedades dos manicômios", contribuindo, desse modo, para desarticular " a outra face da clausura".

Acreditamos, com isso, na necessidade de assegurar e reconhecer a legitimidade da loucura como experiência única, oferecendo possibilidades para que o próprio paciente sustente sua diferença, sem que, para isso, precise excluir-se socialmente. Portanto, trata-se de garantir condições para que o sujeito encontre formas inclusivas de estar fora, estando dentro 13 e, dessa forma, conquiste o lugar social a que tem direito.

Para tanto, é imprescindível que se opere a escuta desses pacientes, já que são os maiores envolvidos na política de desospitalização, que, como qualquer outra política, está permeada pelo jogo de forças, desejos, interesses e, portanto, por relações de poder que atravessam a malha das relações sociais.

A desospitalização, como uma política instituída pelos serviços de saúde mental, deve considerar tanto os aspectos subjetivos dos pacientes quanto o universo social e cultural no qual se encontram. Quando reconhecemos esse fato, admitimos, sem dificuldade, que pretender a transformação da instituição psiquiátrica sem considerar os pontos de sustentação que a própria sociedade lhe oferece é recair na ilusão de que, pela técnica, seria possível modificar a realidade, cuja natureza - social e histórica - deu origem a essas mesmas técnicas. Caso não exista esse cuidado, tal como uma sombra, as práticas atuais possivelmente poderão engendrar mecanismos mais sutis de controle do desvio e de regulação normatizante.

Os achados desta pesquisa oferecem indicações importantes que podem contribuir na elaboração de futuras políticas de saúde mental, como, por exemplo, a política em curso da desospitalização. Além disso, fornecem subsídios para um entendimento clínico e social a respeito da experiência da loucura e de seu respectivo tratamento, que deve, de fato, garantir o exercício da cidadania, a expressão da subjetividade e a reafirmação do valor da vida dos portadores de sofrimento mental. 


\section{Resumo}

O presente trabalho justifica-se à medida que se constata o número elevado de pessoas internadas em hos pital psiquiátrico, embora exista a atual proposta de desospitalização. Este estudo objetivou analisar os fatores envolvidos na recusa da desospitalização a partir do relato de pacientes internos, em um hospital psiquiátrico, com diagnóstico de esquizofrenia e capacidade verbal preservada. Segundo escolha aleatória, foi realizada uma entrevista semi-estruturada com seis pacientes. As entrevistas, posteriormente, foram submetidas à análise de conteúdo temática. Após leitura das transcrições, foram extraídos os seguintes núcleos temáticos: a sensação de liberdade ainda que internado, a proteção concreta e subjetiva que o hospital oferece, o modo de vida asilar incorporado pelos pacientes. Os achados podem contribuir para a elaboração de políticas públicas em saúde mental e para a compreensão da dinâmica subjetiva dessa população.

Saúde Mental; Esquizofrenia; Hospitais Psiquiátricos

\section{Colaboradores}

V. Machado coletou e realizou a análise dos dados da pesquisa, redigiu a versão preliminar do trabalho e participou da edição e revisão da versão final do artigo. A. R. X. Manço participou nas análises e na edição do artigo. M. A. Santos contribuiu na análise dos dados e na revisão final do artigo.

\section{Referências}

1. Bandeira M. Desinstitucionalização ou transinstitucionalização: lições de alguns países. J Bras Psiquiatr 1991; 40:335-60.

2. Aquino R. A loucura no novo milênio. http://www. datasus.gov.br/cns/temas/tribuna/a_loucura_no _novo_milenio.htm (acessado em 03/Dez/2002).

3. Lobosque AM. Experiência da loucura. Rio de Janeiro: Garamond; 2001.

4. Amarante P. Novos sujeitos, novos direitos: o debate em torno da reforma psiquiátrica. Cad Saúde Pública 1995; 11:491-4.

5. Basaglia F. A instituição negada: relato de um hospital psiquiátrico. 2a Ed. Rio de Janeiro: Graal; 1991.

6. Basaglia F. A psiquiatria alternativa. São Paulo: Editora Brasil Debates; 1979.

7. Preti D, organizador. Análise de textos orais. São Paulo: Humanitas Publicações; 1994.

8. Bardin L. Análise de conteúdo. Lisboa: Edições 70; 1977

9. Fé IM. A doença mental e autonomia. Revista de Bioética 1998; 6:71-9.

10. Mannoni M. O psiquiatra, seu "louco" e a psicanálise. Rio de Janeiro: Jorge Zahar Editor; 1981.

11. Amarante P. O homem e a serpente: outras histórias para a loucura e a psiquiatria. Rio Janeiro: Editora Fiocruz; 1996.

12. Calligaris C. Introdução a uma clínica diferencial das psicoses. Porto Alegre: Artes Médicas; 1989.

13. Lobosque AM. Princípios para uma clínica antimanicomial. São Paulo: Editora Hucitec; 1997.

14. Barros DD. Cidadania versus periculosidade social: a desinstitucionalização como desconstrução de um saber. In: Amarante P, organizador. Psiquiatria social e reforma psiquiátrica. Rio de Janeiro: Editora Fiocruz; 1994. p. 171-93.

15. Lobosque AM. Clínica em movimento: por uma sociedade sem manicômios. Rio de Janeiro: Garamond; 2003.

16. Pelbart PP. Manicômio mental: a outra face da clausura. In: Lancetti A, organizador. Saúde e loucura. v. 2. São Paulo: Editora Hucitec; 1990. p. $132-40$.

Recebido em 01/Set/2004

Versão final reapresentada em 11/Jan/2005

Aprovado em 04/Fev/2005 